\title{
OPPORTUNITIES AND CONSTRAINTS IN ONLINE PHYSICAL EDUCATION
}

\author{
Ioan AUGUSTIN ${ }^{1 *}$, Nicu OLOGEANU ${ }^{2}$, Doina CROITORU ${ }^{3}$ \\ ${ }^{1}$ City Hall, Alexandria, Romania \\ ${ }^{2}$ ISJ Teleorman, Alexandria, Romania \\ ${ }^{3}$ National University of Physical Education and Sport, Faculty of Physical Education and Sport, Bucharest, \\ Romania \\ *Corresponding author: augustin.ioan@alexandria.ro
}

https://doi.org/10.35189/dpeskj.2021.60.3.2

\begin{abstract}
In this difficult pandemic period, the imminent changes have mainly affected physical activity and particularly physical education lessons at all education levels. This is a reality for both urban and rural schools. While the transmission of information through the online environment is done without too many obstacles in other purely theoretical teaching activities, in physical education, the transmission and acquisition of knowledge but especially evaluation have been and are still affected. In this paper, we aimed to identify the main constraints in conducting online physical education lessons from the subjective point of view of students, parents and teachers. We also set out to make a comparison between the views of urban and rural actors. The assessed period was from March to December 2020, when the activity took place only online due to the "red code". The survey was carried out between December 7-18, the last school week of the year. The conclusion showed that parents, teachers and students had different opinions on the main difficulties encountered during this period. Students' responses mainly highlighted their poor knowledge of using educational platforms, inappropriate space for practical activities and lack of connection devices. Parents' responses focused on both their impossibility of supervising children and reduced possibilities of supporting them due to lack of knowledge or time. From the perspective of teachers, we identified their impossibility of actively monitoring students' health and problems related to the verification of compliance with labour protection rules during practice.
\end{abstract}

Keywords: school, SARS-CoV-2 pandemic, opinions, parents, children.

\section{Introduction}

In this difficult pandemic period, the imminent have mainly affected practical activity and particularly school physical education in both rural and urban areas. While the transmission of information through the online environment is done without too many obstacles in other purely theoretical teaching activities, in physical education, the transmission and acquisition of knowledge but especially evaluation have been and are still affected. Killian et al. (2021) highlight that "Distance learning is something many physical educators never thought they would have to do, given the practical and philosophical contradictions inherent in teaching and learning movement-based content through a computer" (p. 11).

Physical education and sport should be considered a very important part of life as they "help to improve the person, help to strengthen the health and efficient functioning of the workforce, which ultimately contributes to the full economic progress of the country" (Juraevich, 2020, p. 181).

Regarding online teaching, Aktop and Karahan (2012) state: "In service training activities for PE teachers concerning the new curriculum and new teaching approaches and methods should be done more frequently" (p. 1913). Following this line, during the period in which the 
state of emergency and subsequently the state of alert were declared in Romania, pre-university and university students were able to continue their studies in the online environment according to Order no. 4135 of 21.04.2020 issued by the MEC (Ministry of Education and Research). In these difficult periods, Romanian education went through various episodes of other legislative regulations by which the above ministry tried to guide the course of educational actors.

In current online teaching, some of the challenges are "based on the experiences 'forced' upon us by the pandemic" (Chang \& Reekie, 2021, p. 5). It is recognised by the participants in the instructive-educational process (teachers, students of all ages and university students) that the effectiveness of teaching has been affected. If we were to identify the level of education at which the learning effectiveness was most severely affected, then we could certainly say that the work of pre-university students has been most difficult to influence by the online teaching system. To teach knowledge and train skills and abilities has become a challenge for teachers working with larger groups and even impossible in the case of very young students. In the same context, D'Isanto and D'Elia (2021) showed in their research that "Physical education in primary school was the discipline that suffered, perhaps more than any other, from the lack of structured physical activities and, above all, of interpersonal relationships" (p. S1534).

The results of a recent study (Safruddin et al., 2021) reveal that "the students' locomotor movement skills were in the very poor category, the non-locomotor motion was not good, and the manipulative movement was in a good category" (p. 314). On the other side, Vilchez et al. (2021) found a teacher's optimistic point of view: "Participants identified effective strategies, challenges, and recommendations for the future. Participants felt optimistic about their ability to provide quality physical education via distance learning, given the necessary supports, and perceived that they played a critical role in supporting student health during the COVID-19 pandemic" (p. 541).

To carry out the teaching-learning activity, pre-university students benefited from the Google Classroom and Google Meet educational platforms through which they continued their learning. It is also well known that a pre-university student cannot spend in front of the monitor a time equivalent to that spent in the classroom, which is why educators have passed on tasks to parents regarding the organization of children's time and activities, with a focus on supporting their positive emotional state as a priority.

Primary school students constantly need the guidance of teachers and parents to perform their school tasks. Teaching at this level of education was particularly affected by the direct lack of communication between teacher and student. The findings of Fletcher and Bullock (2015) also indicate that "the perceived disembodiment of teaching and learning online affected how we fostered relationships with students and responded to problems of practice" (p. 690).

Primary school students carried out their school activities using some educational platforms such as Google Classroom, Google Meet, Zoom or Microsoft Levels through synchronous or asynchronous activities. Thus, in addition to online meetings with students, teachers uploaded daily on dedicated platforms homework and worksheets for their students, but also materials such as videos, music videos for children, tutorials for drawing or practical activities, images, online teaching games, online exercises, useful links for performing the tasks or homework received, etc. 
Students were able to communicate with their teachers both during online meetings on Google Meet and by directly uploading their homework or writing to their teachers and classmates on the platforms used.

In lower secondary education, students benefited from the systematisation and communication of the necessary knowledge as well as the organization and verification of learning. As a rule, classes were conducted online using well-known educational platforms: Google Classroom, Google Meet, Zoom, Microsoft Teams, etc. The teaching-learning activity also took place synchronously and asynchronously through direct student-teacher meetings and early distribution of study materials: summaries, useful links, educational videos on YouTube or filmed by the teacher, PPT presentations, audio or video tutorials, questionnaires, etc.

In the process of organizing online education, difficulties were identified in approaching predominantly practical subjects/activities, physical education and sport being perhaps the school subject with the most constraints. As Sieber (2005) underlines, "Effective online teaching focuses on processes of learning rather than outcomes" (p. 329), as outcomes are very difficult to evaluate, especially in physical education.

Online schooling and particularly physical education classes are a challenge for students and teachers alike. For physical education teachers, it is a real attempt to find ways to capture students' interest and meet the curricular requirements in the online environment. We subscribe to Dyson (2014) and agree to the idea that "Physical education is much broader than just physical activity, and we harm the future potential of our field if we adopt a narrow agenda" (p. 144).

In this paper, we aimed to assess the impact of using online activity during the pandemic on school activities, especially in addressing physical education and sport lessons.

\section{Methodology}

\section{Participants}

The constraints and opportunities were identified using a local survey addressed to a sample of 30 students (11 girls and 19 boys, average age: 12 years), 30 parents (21 women and 9 men, average age: 33 years) and 30 teachers ( 24 women and 6 men, average age: 46 years).

The research was conducted in two schools, one from an urban area ("Zaharia Stancu" Middle School, Roșiori de Vede, Teleorman), and the other from a rural area (Nanov Middle School, Teleorman). Roșiori de Vede is one of the oldest towns in Romania with about 27,000 inhabitants, and Nanov is a village with about 4,000 inhabitants.

The period assessed was between March and December 2020, and the application period was from 7 to 18 December 2020.

\section{Method}

We used a qualitative approach - the focus group survey based on lived experience. 


\section{Results}

\section{A. Main problems identified}

a1. From the students' perspective

- Urban school:

- Poor knowledge of using educational platforms;

- Inappropriate space for practical activities.

- Rural school:

- Poor or no Internet connection - $38 \%$ of surveyed students do not have a stable Internet connection;

- Lack of connection devices - $40 \%$ of surveyed students do not have a device or only have an unusable phone for online activity;

- Poor knowledge of using educational platforms.

a2. From the parents' perspective

- Urban school:

- Impossibility of supervising children - 95\% of surveyed parents are at work during online classes.

- Rural school:

- Poor or no Internet connection;

- Lack of connection devices;

- Reduced possibilities of supporting children due to lack of knowledge or time.

a3. From the teachers' perspective

- Urban school:

- Failure to actively monitor students' health;

- Problems related to the verification of compliance with labour protection rules during practice;

- Lack of experience in choosing the means for teaching online physical education;

- Reduced evaluation possibilities in the online system;

- A tendency to develop monotony;

- Learning elements are predominantly static and especially individual.

- Rural school:

- Failure to actively monitor students' health;

- Problems related to the verification of compliance with labour protection rules during practice;

- Lack of experience in choosing the means for teaching online physical education;

- Reduced evaluation possibilities in the online system;

- A tendency to develop monotony;

- Learning elements are predominantly static and especially individual.

B. Main advantages/opportunities identified by questioning the surveyed educational actors

b1. From the students' perspective

- Urban school:

- Learning focused on the affective and psychomotor fields; 
- Learning based on the analysis of learning strategies and methods rather than just the acquisition of content.

- Rural school:

- Learning focused on the affective and psychomotor fields;

- Learning based on the analysis of learning strategies and methods rather than just the acquisition of content.

b2. From the parents' perspective

- Urban school:

- Easier communication with teachers via online devices.

- Rural school:

- Easier communication with teachers via online devices.

b3. From the teachers' perspective

- Urban school:

- Opportunity for personalised/individualised teaching;

- Opportunity to use demonstration videos with the possibility of low-speed scrolling, which is ideal for the analysis of motion learning algorithms;

- Materials available in virtual libraries or on YouTube channels, multiple possibilities to choose the most useful ones.

- Rural school:

- Opportunity for personalised/individualised teaching;

- Opportunity to use demonstration videos with the possibility of low-speed scrolling, which is ideal for the analysis of motion learning algorithms;

- Materials available in virtual libraries or on YouTube channels.

\section{Discussion}

Studies aiming to examine the use of telecourses in adult and higher education are not new (Machtmes \& Asher, 2000; Mohnsen, 2012; Daum \& Buschner, 2012). Remote schooling does not only have constraints/disadvantages but has become an opportunity to define even more clearly the roles of both the student as an active part of their own training and the teacher, who should become a main facilitator of education, inspire learning and guide students towards goal achievement rather than controlling them, reorganise and systematise content so that it becomes relevant, change their teaching style with a focus on collaboration and the development of students' autonomy, creativity and accountability in decision-making. Distance learning has shown that an effective connection with students' parents as essential factors of education, who can influence children's attitudes towards school, is as important as the connection with the student. Mosston and Ashworth (2008) conclude that delayed feedback might lead the child to practise a skill incorrectly, thus hindering rather than enhancing the long-term development of that skill.

During this period, teachers have identified and used all means of communication with their students, which is not quite easy, especially where there is no Internet connection or connection devices that allow online classes are missing. In these situations, telephone services were used, communication being achieved by means of messages or phone calls through which students 
received instructions on how to complete tasks, clarifications and answers to their questions. In remote localities, teachers distributed worksheets for students to continue learning.

It is certain that both teachers and students have substantially improved their digital skills, which has changed the quality of both the teaching-learning process and the student-familyteacher relationship. Civil society has also become more involved, offering suggestions for improving the quality of digital teaching tools as well as distance learning methods.

In most cases, teachers were at the beginning of their self-taught period, learning from their own experience, communicating with colleagues, studying materials and watching tutorials for the use of digital tools and platforms needed to conduct distance education. Along the way, they wanted and began to access training courses organized by the County School Inspectorates through the Teaching Staff Houses or supported by other training providers.

With this state created by the emergence of the pandemic (a state with which modern society was not accustomed, and we can mention here the states of emergency, alert or other forms of restriction of freedoms in the context of SARS-CoV-2), all of us, but especially students, have confused our perception of normality, acquired automatisms and the first steps of learning, being projected into a new social and economic paradigm.

The imposed model has taught us to protect ourselves more and more efficiently from a health and social point of view but has also given rise to real dramas. New stressors have emerged such as distance from friends (including lack of socialisation, which is so necessary for a harmonious mental and physical development), the impossibility of creating a direct relationship (based on the transmission of information through non-verbal language) and especially the much-needed exemplification in physical education and sport. Consequently, all of this has led to the loss of a germinal period in which the body of knowledge, motor skills and abilities were affected both horizontally and vertically. We can add the loss of love for movement and also the recession of the grassroots area of selection for high-level sports.

The thermometry measures existing in all institutions, the provision of circuits and traffic flows, the unprecedented hygiene measures (such as the mandatory wearing of masks or the free supply of disinfectants by mayors) have not led to a total return to normality even when the incidence of the disease was close to zero in each locality. Therefore, the pandemic period will represent for these generations a period of trials, of restrictions with medium- and longterm consequences, from a social, economic and psychological point of view, on the individual's well-being and integration into society. But these consequences are also reflected in the sporting life where important stages in the athletic training are lost as well as the chance of maintaining an optimal health status through exercise; moreover, the interest in the product called "sport" may decline, some people being even deprived of the opportunity to get a taste for it. We think that permanent adaptation to the needs of students is required in conducting the instructive-educational process. We have in mind the periods that will come with possible restrictions, such as the frightening "wave 4". Only this adaptation can save the rather abstract form of conveying information from the transmitter to the receiver, which is currently called "online teaching process", and thus turn the physical education and sport class into one of the most beloved classes attended by all students.

Our study showed that, from the students' point of view, the main problems identified in rural and urban schools were vastly different. Urban students had problems with knowledge of educational platforms and a too small space for physical activities, while those in rural areas 
mainly identified problems related to access to the online environment - Internet connection or lack of a device.

Whereas in urban areas the main problem of parents was their impossibility of supervising children, in rural areas, the parents' problems were similar to those expressed by their children: poor or no Internet connection and lack of connection devices.

The views of physical education teachers from the two schools were more than similar. They highlighted things about children's safety and well-being (failure to actively monitor students' health; problems related to the verification of compliance with labour protection rules during practice; a tendency to develop monotony; predominantly static and especially individual learning elements) and their own limitations (reduced evaluation possibilities in the online system; lack of experience in choosing the means for teaching online physical education).

From the teachers' point of view, our findings converge with the idea expressed by Daum et al. (2021): "The social connectedness between teacher-student and student-student, which is inherently lacking in distance learning, is an important consideration for teachers" (p. 5).

As a surprise for us, the advantages identified by questioning the surveyed educational actors are the same for both rural and urban schools. Even though the expressions were different, by synthesising the responses, we concluded that the ideas were similar. We underline that, from all parents' point of view, there is a single advantage, namely easier communication with teachers via online devices.

We think that the Romanian education system is unlikely to return to its pre-pandemic state. This online schooling period has taken quite a long time for teachers and students to acquire new online communication skills that will certainly be used in the future. What originally started as the opening a "box of worms" is very likely to become a pivot point in the transformation of the Romanian education system. From an extremely optimistic point of view, we believe that the programs equipped with online means of communication that have appeared as emergency solutions in this period will show their results in a few years. To these programs, we should add the individual effort of teachers who spent a lot of time watching tutorials that have improved their online teaching ability and attended organized training courses funded by local authorities or from their own funds.

Online schooling has demonstrated once again that the relationships established between people, the concern for others, communication (i.e., attitudes and social values), which should form the basis of the well-known paradigm of effective and quality education, are more important than the theoretical notions that are sometimes mechanically acquired by students.

We recognise the limitations of our study, but the current possibilities have not allowed us to expand it to a larger scale. We just wanted to approach a subsection of the national education system to which we had access. Even if the results obtained cannot be generalised at national level, they can be used as a starting point for near-scale research and can provide an initial case study.

\section{Conclusion}

In order to respond to the new needs of organizing the teaching process, teachers should use not only their experience gained during this period in this new context but should become more creative, proposing tasks that highlight students' interests, needs and creativity. Regarding 
school physical education and generally physical activities (PA), we agree with Gobbi et al. (2020): 'It is probably needed to consider the COVID-19 pandemic as an 'opportunity' to restore the role of PE in youths' lives, with regards to the promotion of PA" (p. 12).

Our conclusion in terms of evaluation confirms the idea from the study by Baena-Morales et al. (2021): "Regarding the evaluation, a high percentage of teachers neither planned it nor found it feasible" (p. 388). The pandemic period and the conduct of online lessons have shown how important lifelong learning is, especially for the professional development of teachers.

Even though switching to online mode tested our patience, creativity and inventiveness, the pandemic period highlighted the differences between the opportunities provided to students in rural and urban areas.

Our findings show that parents, teachers and students have different views on the main difficulties encountered during this period. Students' responses mainly highlighted their poor knowledge of using educational platforms, inappropriate and inadequate space for practical activities and lack of connection devices. Parents' responses focused on their impossibility of supervising children and reduced possibilities of supporting children due to lack of knowledge or time. It is critical to train parents to support their children, especially in rural areas. This task can be exceedingly difficult, almost impossible for a parent with several children of different ages. It is important that access to the online environment is offered to each child in terms of both connection and equipment. Of all the countries of the European Union, Romania allocates one of the lowest percentages of GDP for education (Eurostat, 2021). Education needs more funding, greater allocation from the state budget and a reallocation of resources within the existing budget.

From the teachers' perspective, we identified their impossibility of actively monitoring students' health and problems related to the verification of compliance with labour protection rules during practice. As the problems are different in rural and urban schools, the advantages identified are the same for students, parents and teachers.

Even if the new regulations proposed by the Romanian Ministry of Education for the start of the 2021-2022 school year suggest the physical presence of children in all classes, including physical education, the lessons learned during the pandemic period should not be forgotten.

\section{References}

Aktop, A., \& Karahan, N. (2012). Physical education teacher's views of effective teaching methods in physical education. Procedia - Social and Behavioural Sciences, 46, 19101913. https://doi.org/10.1016/j.sbspro.2012.05.401

Baena-Morales, S., Lopez-Morales, J., \& Garcia-Taibo, O. (2021). La intervención docente en educación física durante el periodo de cuarentena por COVID-19 [Teaching intervention in physical education during quarantine for COVID-19]. Retos, 39, 388-395. https://doi.org/10.47197/retos.v0i39.80089

Chang, S. H., \& Reekie, S. H. (2021). Teaching college physical activity courses online: Some considerations. Journal of Physical Education, Recreation \& Dance, 92(5), 5-8. https://doi.org/10.1080/07303084.2021.1899538

Daum, D. N., \& Buschner, C. (2012). The status of high school online physical education in the United States. Journal of Teaching in Physical Education, 31(1), 86-100. https://doi.org/10.1080/07303084.2012.10598727 
Daum, D. N., Goad, T., Killian, C. M., \& Schoenfeld, A. (2021). How do we do this? Distance learning in physical education (Part 1). Journal of Physical Education, Recreation \& Dance, 92(4), 5-10. https://doi.org/10.1080/07303084.2021.1886836

D'Isanto, T., \& D'Elia, F. (2021). Primary school physical education in outdoor during COVID-19 pandemic: The perceptions of teachers. Journal of Human Sport and Exercise, 16(3proc), S1507-S1521. https://doi.org/10.14198/jhse.2021.16.Proc3.67

Dyson, B. (2014). Quality physical education: A commentary on effective physical education teaching. Research Quarterly for Exercise and Sport, 85(2), 144-152. https://doi.org/10.1080/02701367.2014.904155

Eurostat. (2021). General expenditure on education. https://ec.europa.eu/eurostat/statisticsexplained/index.php?title=Government_expenditure_on_education\#Expenditure_on_.27ed ucation. 27

Fletcher, T., \& Bullock, S. M. (2015). Reframing pedagogy while teaching about teaching online: A collaborative self-study. Professional Development in Education, 41(4), 690-706. https://doi.org/10.1080/19415257.2014.938357

Gobbi, E., Maltagliati, S., Sarrazin, P., Di Fronso, S., Colangelo, A., Cheval, B., EscrivaBoulley, G., Tessier, D., Demirhan, G., Erturan, G., Yüksel, Y., \& Carraro, A. (2020). Promoting physical activity during school closures imposed by the first wave of the COVID19 pandemic: Physical education teachers' behaviors in France, Italy and Turkey. International Journal of Environmental Research and Public Health, 17(24), 1-15. https://doi.org/10.3390/ijerph17249431

Juraevich, M. J. (2020). Actual problems of teaching physical culture in schools. Asian Journal of Multidimensional Research, 9(11), 181-187. http://dx.doi.org/10.5958/2278-4853.2020.00287.6

Killian, C. M., Daum, D. N., Goad, T., Brown, R., \& Lehman, S. (2021). How do we do this? Distance learning in physical education (Part 2). Journal of Physical Education, Recreation \& Dance, 92(4), 11-17. https://doi.org/10.1080/07303084.2021.1886838

Machtmes, K., \& Asher, J. W. (2000). A meta-analysis of the effectiveness of telecourses in distance education. American Journal of Distance Education, 14(1), 27-46. https://doi.org/10.1080/08923640009527043

MEC. (2020). Ordin nr. 4135 din 21 aprilie 2020 privind aprobarea Instrucțiunii pentru crearea și/sau întărirea capacității sistemului de învățământ preuniversitar prin învăţare on-line [Order no. 4135 of 21 April 2020 on the approval of the Instruction for creating and/or strengthening the capacity of the pre-university education system through online learning]. Monitorul Oficial, 331/23 aprilie 2020.

http://legislatie.just.ro/Public/DetaliiDocument/224975

Mohnsen, B. (2012). Implementing online physical education. Journal of Physical Education, Recreation \& Dance, 83(2), 42-47. https://doi.org/10.1080/07303084.2012.10598727

Mosston, M., \& Ashworth, S. (2008). Teaching physical education. https://spectrumofteachingstyles.org/assets/files/book/Teaching_Physical_Edu_1st_Online .pdf

Safruddin, S., Nasaruddin, N., Widodo, A., Sobri, M., \& Radiusman, R. (2021). Students' basic movement skills in physical education during the online learning. In Proceedings of the 2 nd Annual Conference on Education and Social Science (pp. 314-317). Atlantis Press. https://dx.doi.org/10.2991/assehr.k.210525.097

Sieber, J. E. (2005). Misconceptions and realities about teaching online. Science and Engineering Ethics, 11(3), 329-340. https://doi.org/10.1007/s11948-005-0002-7

Vilchez, J. A., Kruse, J., Puffer, M., \& Dudovitz, R. N. (2021). Teachers and school health leaders' perspectives on distance learning physical education during the COVID-19 pandemic. Journal of School Health, 91(7), 541-549. https://doi.org/10.1111/josh.13030 